\title{
Surface deformation of 0206 Hualien earthquake revealed by the integrated network of RTK GPS
}

\author{
Bo-Lin $\mathrm{Wu}^{1}$, Jiun-Yee Yen $^{1}$, Shao-Yi Huang ${ }^{1,2}$, Yu-Ting Kuo ${ }^{2}$, and Wen-Yen Chang ${ }^{1}$ \\ ${ }^{1}$ Department of Natural Resources and Environmental Studies, National Dong Hwa University, Hualien County, Taiwan \\ ${ }^{2}$ Institute of Earth Sciences, Academia Sinica, Taipei City, Taiwan
}

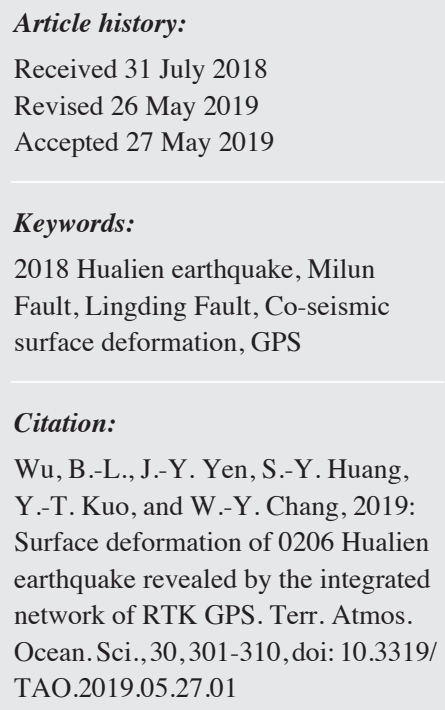

Wu, B.-L., J.-Y. Yen, S.-Y. Huang, Y.-T. Kuo, and W.-Y. Chang, 2019: Surface deformation of 0206 Hualien earthquake revealed by the integrated network of RTK GPS. Terr. Atmos. Ocean.Sci., 30,301-310, doi: 10.3319/ TAO.2019.05.27.01

\begin{abstract}
At 23:50 (local time, UTC+8) on 6 February 2018, a shallow earthquake of magnitude 6.2 on Richter scale occurred at the coastal area of Hualien, inducing significant fault activities on the Milun and Lingding Faults, and caused ruptured surface, damaged infrastructures and collapsed buildings. To understand the influence of the earthquake, this paper investigates the affected areas after the earthquake by using the network RTK to measure more than one hundred benchmarks set up by various government agencies for surface deformation measurement. The results of the investigation showed that the Milun Terrace moved along the Milun Fault in a left lateral motion with a reverse component in the northern part of the terrace for about $70 \mathrm{~cm}$ relative to the west side of the fault. Most of the reported damage occurred near the fault. Around the Lingding Fault, most reported surface ruptures and landslides occurred at the northern section of the Coastal Range, which moved northward for about $50 \mathrm{~cm}$ relative to the west side of the fault. Surface rupture of the Lingding Fault was observed from the northern tip of the Coastal Range to near Yuemei Bridge. In between two faults, the area showed significant subsidence regardless of their directions of horizontal coseismic motion. The subsidence can be as high as $50 \mathrm{~cm}$ near the southern end of the Milun Fault.
\end{abstract}

\section{INTRODUCTION}

At 23:50 on 6 February 2018, an earthquake of magnitude 6.2 occurred to the northeast of Hualien County Hall, Taiwan (epicenter located at $24.14^{\circ} \mathrm{N}, 121.69^{\circ} \mathrm{E}$ ). Intensity (on Central Weather Bureau scale) was reported as high as 7 at several seismic observatory stations around Hualien (Central Weather Bureau 2018). The earthquake occurred with a shallow depth of merely $6 \mathrm{~km}$ and induced activities of the adjacent Milun and Lingding Faults, causing surface ruptures and damage of buildings at urban areas of Hualien City, the north part of the Coast Range (Figs. 1,2). Although most of the surface ruptures occurred along the east-dipping Milun Fault, the seismogenic origin appeared to be another west-dipping structure situated offshore of Hualien. Thus, many post-earthquake investigations mainly focused on the distribution of earthquake sequences, the interpretation of focal mechanism, the extent of surface rupture, the relation between building damages, the seismic waves and so forth

\footnotetext{
* Corresponding author

E-mail:jyyen@gms.ndhu.edu.tw
}

(Guan et al. 2018; Huang et al. 2018; Jiang et al. 2018; Sun et al. 2018; Wang et al. 2018). These surveys mostly investigate the Milun Fault and the urban areas of Hualien where the surface damage became diffused and showed distributed slip. South of Hualien City, not much has been discussed except for the Hualien Bridge where significant left-lateral offset of the Lingding Fault was presented. Although the Nanbin area did not have significant damages reported, this area has undergone a significant deformation, and was a crucial area to understand how the Milun Fault and the Lingding Fault interact with each other.

Through field observation and geodetic survey, this paper intends to put more emphasis on discussing the relationship between the southern section of the Milun Fault and the northern section of the Lingding Fault by characterizing their styles of surface deformation.

\section{GEOLOGICAL BACKGROUND}

The mainshock of 0206 Hualien earthquake was 

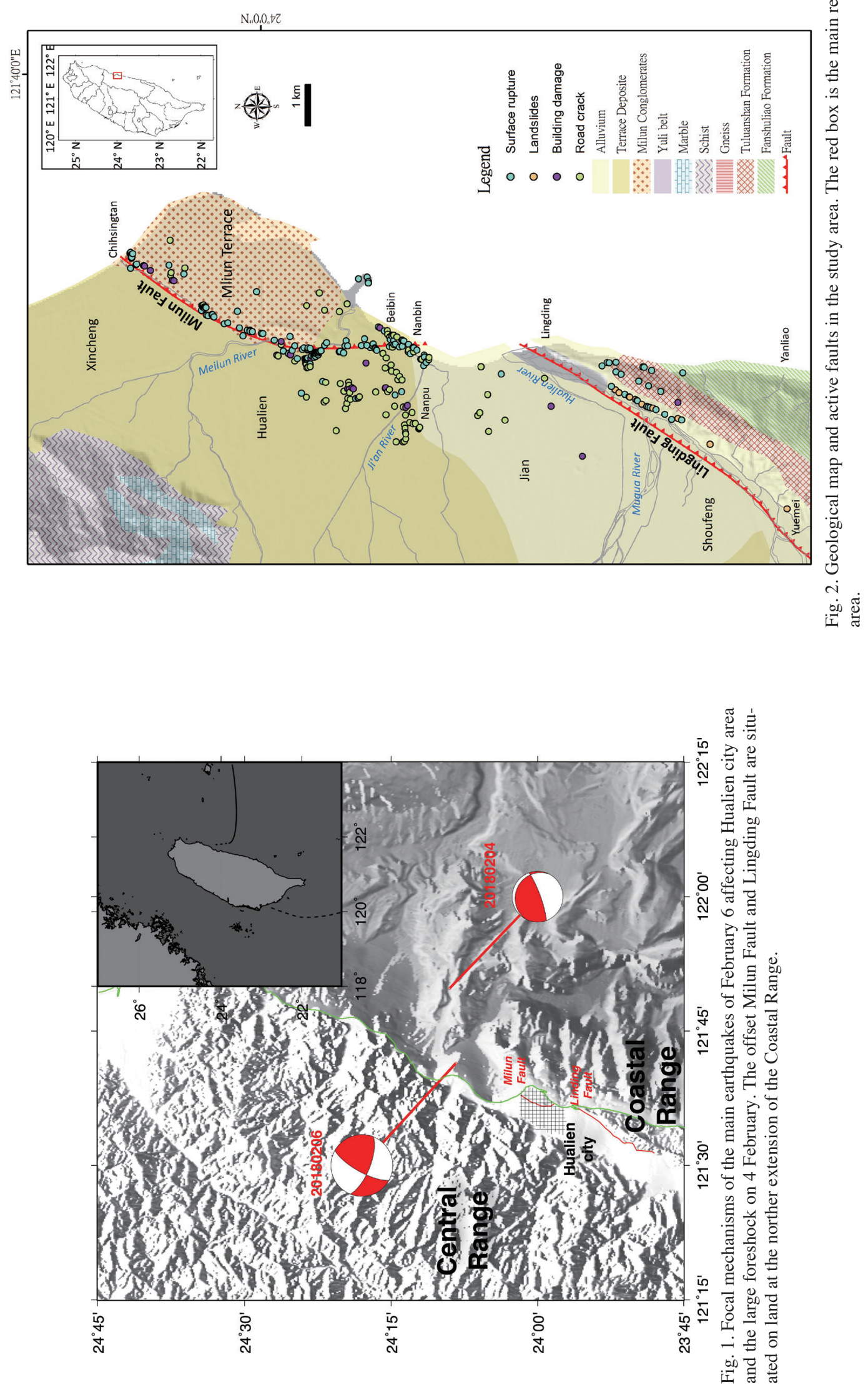
located at the offshore alluvial fan of the Liwu River. Several foreshocks occurred around this area before the $M_{L} 6.2$ mainshock, e.g., the $\mathrm{M}_{\mathrm{L}} 5.8$ earthquake on 4 February. According to the fault plane solution of Central Weather Bureau (2018), the two possible fault planes oriented either 35 degrees with a dip of 56 degrees to the northwest or 110 degrees with a dip of 69 degrees to the south. As inferred from the distribution of the aftershock, which ranged from the offshore Milun Fault to the Great Hualien area on land, the seismogenic fault should be a strike-slip fault with a westward dip in a northeast-southwest direction. The shock induced the activities on the Milun Fault and the Lingding Fault and caused a large-scale of surface ruptures along the fault line (Hsu et al. 2018, 2019; Huang et al. 2019; Lin et al. 2019) - mainly concentrated at the north of Hualien County (Fig. 2; Xincheng Township, Hualien City, Ji'an Township and Shoufeng Township). The Hualien area was mainly formed by Holocene alluvial and terrace deposits. The Milun conglomerates of Late Pleistocene was observed at the northeast side of the Milun Terrace, composed of thick layers of conglomerate and sandstone. To the south, the Coastal Range mainly comprises igneous rocks of the Tuluanshan formation from the Late Miocene to the Early Pliocene, the Fanshuliao formation of Pliocene mudstone and sand-shale, and the thick layers of conglomerate, sandstone, alternate layers of sand-shale and mudstone of Paliwan formation from Late Pliocene to the Mid Pleistocene. The Central Range on the west side was the Tananao metamorphic complex of green schist.

The Milun Fault is a left-lateral fault with a reverse component striking in a direction of north-south and extending from the southwest of the Chihsingtan beach to Hualien City along the west edge of the Milun Terrace. It also further extends to the ocean from Nanbin. The on land part of the fault is approximately $8 \mathrm{~km}$ long (Lin et al. 2009). The Milun Fault was the seismogenic fault of the Hualien earthquake in 1951. According to the report from Taiwan Weather Bureau (1952), the land at the east side of Hualien Airport was uplifted $50 \mathrm{~cm}, 40 \mathrm{~cm}$ at the side of residential houses near Chihsingtan, and $40 \mathrm{~cm}$ at the west foot of Meilun Mountain. Also, near Jiali Village, the east side of the fault moved $40 \mathrm{~cm}$ to the north (Yu 1997). Yu et al. (1990) organized and analyzed the data from 1983 - 1988 and found out that compared to the west side of the fault, the uplift rate of the Milun Terrace was $4.4 \pm 3.3 \mathrm{~mm} \mathrm{yr}^{-1}$ and the horizontal slip rate was $8.5 \pm 3.0 \mathrm{~mm} \mathrm{yr}^{-1}$ to the north. Kao (2016) used the PSInSAR results and organized the past data to infer that the activity of Milun Fault was intermittent. During the earthquake, the hanging wall block of the Milun Fault would be significantly elevated and the uplift rate of inter-seismic period was almost zero (Yen et al. 2011; Kao 2016).

The Lingding Fault could be a left-lateral fault with a reverse component in an approximate direction of NNE. Starting from the Hualien River Estuary, it extends south- westwards along the Coastal Range and the east side of the longitudinal valley, goes through Yuemei, and reaches to Dongfu Village of Guangfu Township in a total length of $30 \mathrm{~km}$ (Chen et al. 2008). There were a series of intermittent linear cliffs on the east side of the fault, originally known as the Yuemei Fault (Lin et al. 2000). Hsu (1955) proposed that as the rivers from the Central Range developed a wide alluvial fan at the north part of the longitudinal valley, the Hualien River was forced to drift to the east side of the valley when the fan grew eastward. The thick alluvial deposit may therefore covered the outcrops of the faults in the longitudinal valley and made it difficult to be observed. Kuo-Chen et al. (2004) re-located the earthquakes of $\mathrm{M}_{\mathrm{L}}>3$ during 1991 and 2002, and the results could not clearly map the underground faults in the northern part of longitudinal valley. There is only a slight indication of a seismic zone with an eastward dip. Chen (1974) had used geodetic data to find out the northeast movement in the northern section of the Coastal Range relative to the Central Range $\left(16-23^{\circ}\right)$ and a relative horizontal misalignment rate of $60-113 \mathrm{~mm} \mathrm{yr}^{-1}$. The measurement results by $\mathrm{Yu}$ et al. (1990) showed a horizontal displacement rate of $28.5 \pm 3.0 \mathrm{~mm} \mathrm{yr}^{-1}$ in the direction of due north $\left(353 \pm 1^{\circ}\right)$.

\section{THE GPS MEASUREMENT AND RESULTS}

Geodetic survey is a common way to understand the patterns of different surface rupture and the degrees of damage occurred in different regions in an earthquake (Yu et al. 2001; Pathier et al. 2003). During the 0206 earthquake, cGPS detected surface deformation near the disaster area (Yen et al. 2019), however, the deformation pattern was only partly revealed because of the uneven coverage and low density of the continuous GPS. Large displacements in the northern segment of the Milun Fault measured in the field were not recorded by the sparsely distributed GPS stations. In this study, we used network RTK GPS to measure benchmarks setup near Hualien city (detailed records of the benchmarks are listed in the supplementary data). These benchmarks were originally setup by various agencies including Hualien City and Hualien County, the $9^{\text {th }}$ River Management Office, and Ministry of Interior for various purposes. These benchmarks were surveyed several times during the past few years. We utilized the large number of benchmarks and measured the location using the network RTK GPS during 8 April to 16 June 2018, for data collection. Although RTK is less accurate compared to campaign GPS and continuous GPS at about $1-10 \mathrm{~cm}$ (Saghravani et al. 2009), it could be adequate to obtain location using this method for coseismic deformation. Our main network RTK station is based in National Dong Hwa University.

The pre-seismic coordinates of the measured sites are shown in Fig. 3, mainly located at the adjacent areas of Hualien County. For comparison, we also plot the campaign 


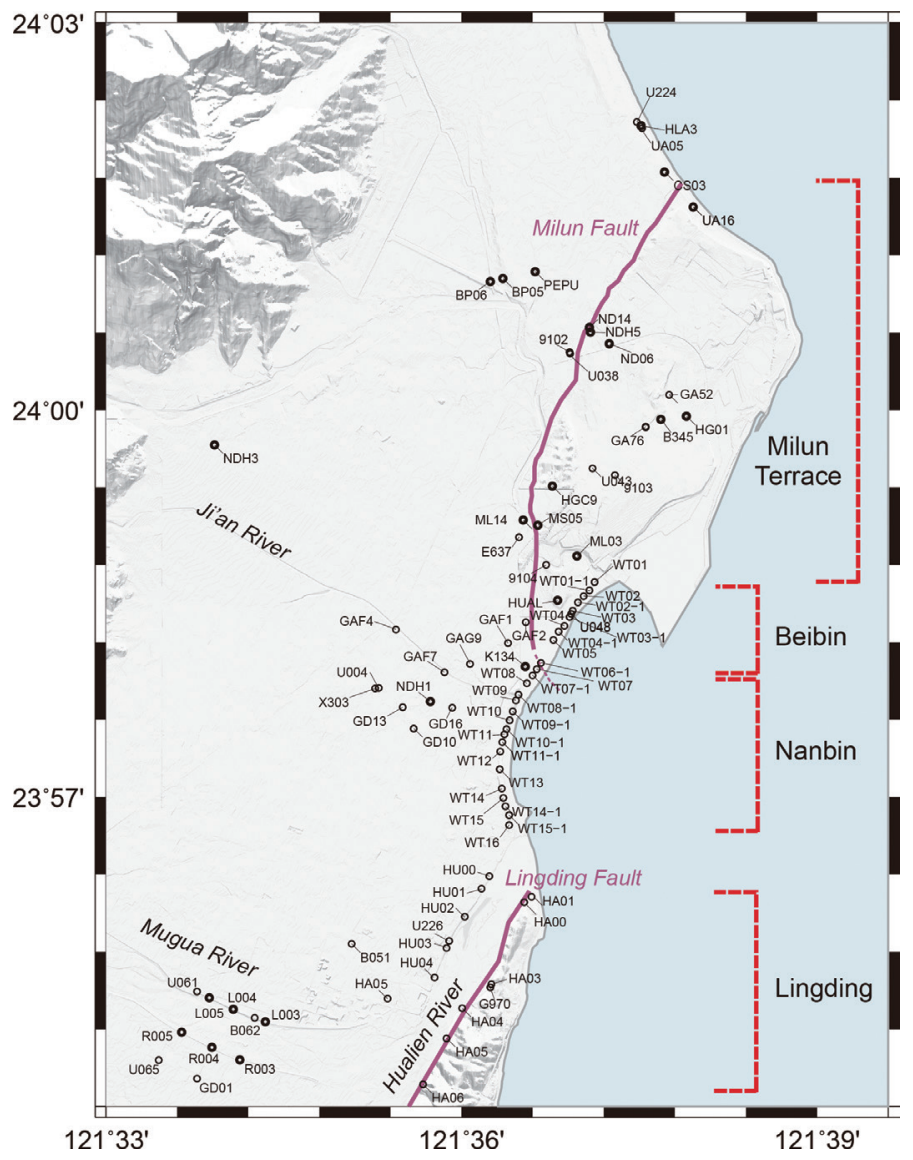

Fig. 3. GPS measurement site. The red dot is the continuous GPS and the campaign GPS stations, and the light blue point is the network RTK measurement site.

GPS and continuous GPS. Reference area between Mugua River and NDHU was selected so that all these data can be compared without any bias. RTK and campaign GPS data used R005 along the Mugua River as the reference point while NDHU station was used for continuous GPS. Orthoheight was used to calculate the vertical difference for all the RTK based data.

The observed results (Fig. 4) showed that in general, continuous, campaign and RTK GPS agreed with each other in both direction and magnitude of measurements, except for very few stations. It showed that the coseismic displacement field in the downthrown block to the northwest of the Milun Fault was moving in a south-southeast direction. The upthrown block, on the other hand, was moving northeast, with distributed measurements showing that the entire hanging wall (including the Milun Terrace and the Beibin area) was moving northeast. In general, the northern part of the terrace has higher displacement (up to less than $80 \mathrm{~cm}$ ) than the southern part (at around $30 \mathrm{~cm}$ ). Further to the south and southwest of the Milun fault (Nanbin area), the downthrown block remained moving southeastwards. The coseismic displacement field to the east of the Lingding Fault was in a north-northeast direction, and the displacement at the west side of the fault was in a southwest direction. The benchmarks along the coast between the Milun Fault and the Lingding Fault generated varied measurements showing the change of motion from north-northeastward (at Beibin section) to southeastward (at Nanbin section) and eventually to slightly southward (at the Lingding Fault).

Both faults showed left lateral displacement with the maximum co-seismic displacement of more than $700 \mathrm{~mm}$. To the south of the Milun Terrace, the maximum displacement value occurred in the Nanbin area where the $9^{\text {th }}$ River Management Office set the benchmarks along the Hualien seawall. The co-seismic displacement fields changed from northward to southward relative to the reference area between the sites of WT07 and WT09-1, and the horizontal displacement decreased from more than $680 \mathrm{~mm}$ at WT03 to approximately $68 \mathrm{~mm}$ at WT08. The co-seismic displacement field of WT09-1 to WT16 mainly changed from southeastward to southward relative to the reference area with the values of horizontal displacement gradually increased from $161 \mathrm{~mm}$ at WT09-1 to $378 \mathrm{~mm}$ at WT16. The distribution on both the direction of motion and the amount of displacement showed that the southern section of the Milun Fault should have passed through the area between WT07 and 


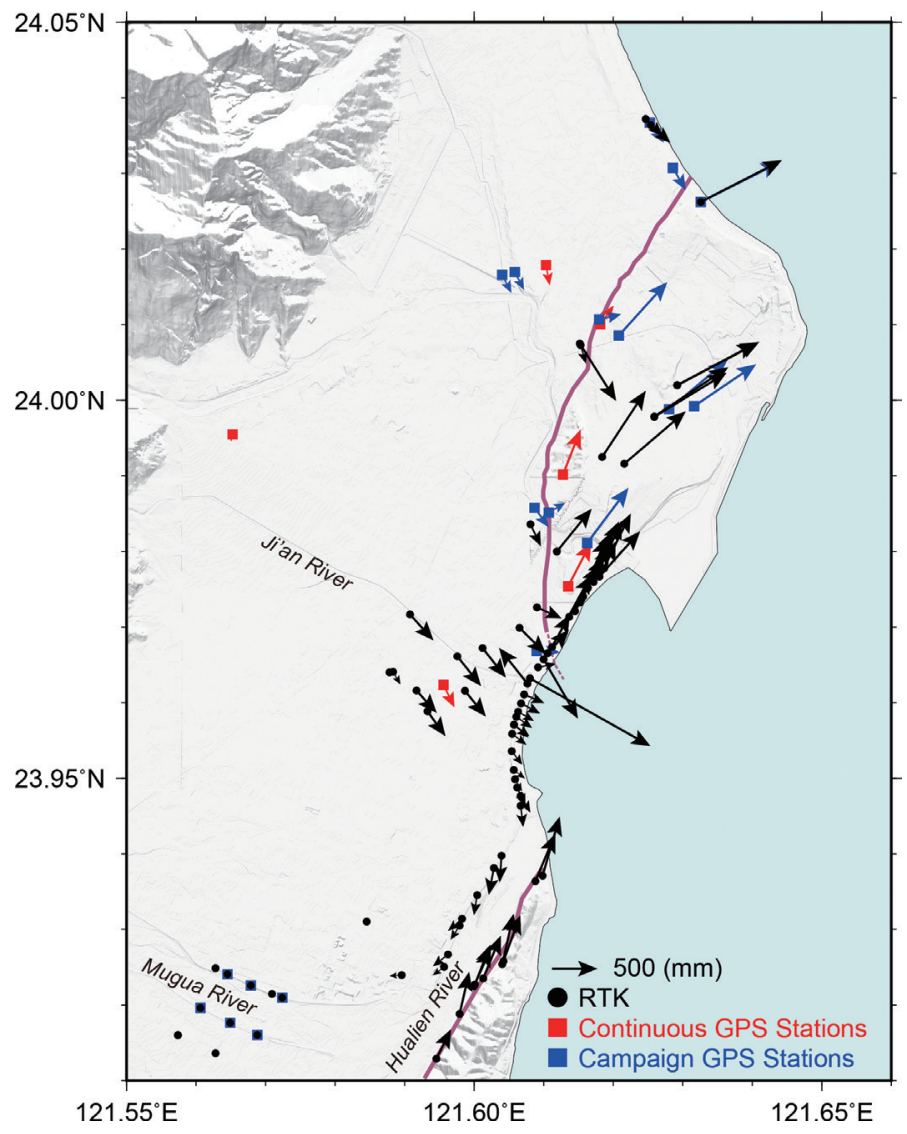

Fig. 4. Horizontal displacements field. The blue arrow is the result of the network RTK measurement, and the red arrow is the result of the continuous GPS and campaign GPS.

WT09-1 and extended into the ocean around the north side of the Ji'an River mouth.

West of the Lingding Fault, the Mugua River merges into the Hualien River and drains the flat plain. The coseismic displacement field in this regime was mostly in the south to southwest direction between 404 and $480 \mathrm{~mm}$, which was also the maximum displacement at the west side of Lingding Fault. To the south of the Mugua River, the displacement decreased southward and the surface rupture ceased to exist near Mizhan Bridge (Fig. 4).

In terms of the vertical displacement (Fig. 5), the Milun Terrace located at the east side of the northern section of Milun Fault had showed greater degree in uplifting. The UA16 near Chihsingtan Village had a maximum displacement of $389 \mathrm{~mm}$. However, the vertical displacement on the west side of the fault was not significant overall. The uplift in the southern part of the Milun terrace to the Beibin area gradually fell below $100 \mathrm{~mm}$, and even turned into subsidence in the area of Nanbin with a maximum of more than $-300 \mathrm{~mm}$ (WT08). Further to the south between the Ji' an River and the Hualien River, the subsidence gradually returned to approximately $-100 \mathrm{~mm}$. To the east of the Lingding fault, the area was dominated by subsidence. The west side of the Lingding fault, close to the Hualien Bridge, showed a significant up- lift (HUA-L04-1, $154 \mathrm{~mm}$ ). However, in the very northern section of the Longitudinal Valley, the changes maybe too small for network RTK to confidently gauge the vertical displacement near this area. Different origins of dataset showed different vertical trend in this reference area.

Based on the results above, Milun Terrace was uplifted and moved in a left lateral fashion along the MilunFault. To the south where the Coastal Range locates, the Lingding Fault moved in a left-lateral fashion while the east of the fault was subsiding relative to the west side of the fault. Offset of the Lingding Fault disappeared near the Yuemei area about $5 \mathrm{~km}$ south of the Hualien Bridge. The southern end of the Milun Fault passed through the Beibin and Nanbin areas and extended from inland toward the ocean. The Beibin area moved towards north-northeast and uplifted as the other part of the Milun Fault. The Nanbin area, on the other hand, experienced subsidence relative to the reference area.

\section{DISSCUSSION AND CONCLUSION}

The Hualien earthquake on 6 February 2018, showed a concentrated surface rupture zone along the Milun Fault and the northern part of the Lingding Fault. Our results from network RTK GPS measured more than one hundred 


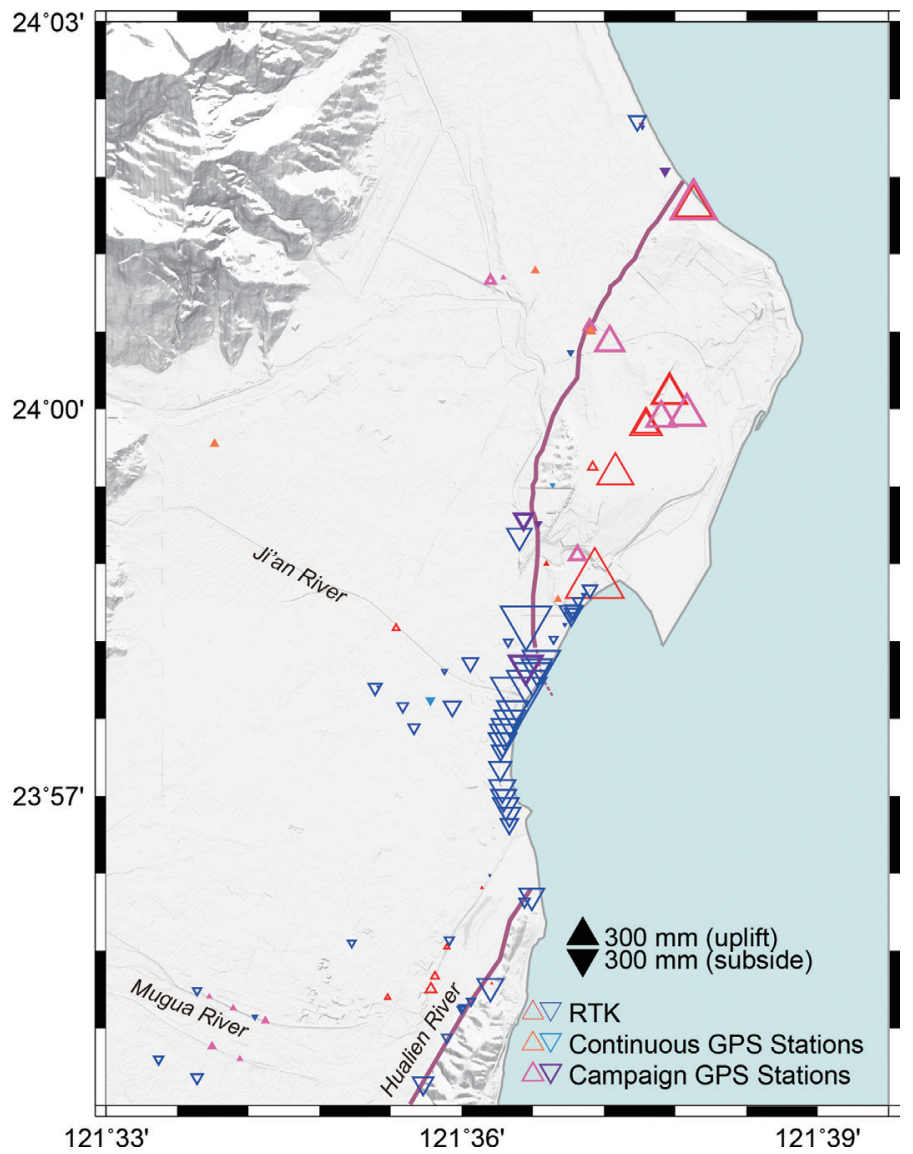

Fig. 5. Vertical displacements field. Red and blue triangles are the result of the network RTK measurement. Pink and light blue triangles are the result of continuous GPS and campaign GPS.

benchmarks in the study area and had a lot more data density compared to continuous GPS and campaign GPS available for this event in this area. The measured data were generally self-consistent with nearby measurements. Field measurements (Hsu et al. 2018, 2019; Huang et al. 2019; Lin et al. 2019) showed that the fault has left lateral motion of around $70 \mathrm{~cm}$ near the Chihsingtan village, which was comparable to our result in the same area. The campaign and continuous GPS data (Yen et al. 2019) were also comparable to our current results as seen in both Figs. 4 and 5.

The compiled map of displacement fields revealed the moving patterns of two distinctive faults and the terranes bounded by the two structures. The Milun Fault situates at the north, generated a curved fault trace concave to the east with significant surface displacements of sinistral and eastdipping reverse components. The Lingding Fault, located to the south, generated a linear fault trace along the west side of the Coastal Range with sinistral displacements. Interestingly, the vertical displacement in the Lingding section showed an unexpected pattern of subsidence on the terrane of the north Coastal Range, where in fact exhibits the topography of higher relief. In between the two faults, the displacement fields changed in both values and direc- tions, representing a transition zone where the strains were adjusted and accommodated due to the interplay of the two faults. In the following paragraphs we will discuss the distribution of displacement fields in detail for the Milun Fault, the Lingding Fault, and the transition zone in conjunction with the seismotectonic implications of the unique patterns.

\subsection{The Distribution of Displacement Fields}

\subsubsection{The Milun Fault}

The Milun Fault was previously characterized as a strike-slip fault with reverse components (Shyu et al. 2016). During the 0206 earthquake, surface ruptures with significant left-lateral and reverse slip were observed along the Milun Fault. Hsu et al. (2018, 2019), Huang et al. (2019), and Lin et al. (2019) all observed that the amount of the surface offset decreased from north to south: the max. horizontal offset is $77 \mathrm{~cm}$ and the max. vertical offset is $60 \mathrm{~cm}$ in the north while the max. horizontal offset is around $20 \mathrm{~cm}$ and the max. vertical offset is about $15 \mathrm{~cm}$ in the south. Their observations focus on the on-site measurements of surface ruptures and therefore are mainly restricted to the areas adjacent to the fault trace. 
The results of our GPS network complement with the previous field observations and provide a broader picture showing the relative movement of the tectonic domains in this regime. Firstly, the whole upthrown block moved toward northeast and the entire downthrown block moved toward southeast. Although the amount of horizontal displacement varied, the moving direction was more or less consistent within each block, characterizing the dramatic left-lateral signatures seen along the fault trace.

Secondly, the decreasing trend of offset not only appeared along the strike of the fault but also occurred in the transverse sense. Our results show that on the upthrown block, both the horizontal and vertical displacement fields along the fault decreased from north to south, in good agreement with the field observations; similarly, the displacement fields across the Milun Terrace (i.e., perpendicular to the fault) display a tendency of decreasing from east to west. The compiled displacement fields show that the entire Milun Terrace uplifted and moved toward northeast. It is also noteworthy that the direction of the fields deflected more to the east in the central and north areas of the terrace.

Last but not least, field observations from $\mathrm{Hsu}$ et al. (2018, 2019), Huang et al. (2019), and Lin et al. (2019) all showed that the surface deformation became more distributed toward the southern part of the Milun Fault and eventually became obscured along the coast of the Nanbin Park. The results from GPS network perfectly picture the location of the proposed fault trace by Huang et al. (2019) as stations GAF1 and GAF2 both show the behavior of the footwall block (moving towards southeast) while station WT07 shows the behavior of the hanging wall block (moving towards northeast). The results from the stations along the Nanbin coast also suggest that the fault extended towards the Pacific because the displacement fields changed from basically northeastward (WT01 to WT07) to disturbed directions (WT07-1 to WT09) then completely southeastward (from WT09-1 onward to the south). It is very likely that the surface rupture passed between the stations WT07 and WT07-1 and extended towards the ocean.

\subsubsection{The Lingding Fault}

The Lingding Fault was considered as the northernmost section of the Longitudinal Valley Fault with reverse and strike-slip components (Shyu et al. 2016). Similar to the Milun Fault, our GPS results reveal the left-lateral motion of the Lingding Fault as the Coastal Range moved towards northeast and the inland area moved towards southwest. The vertical displacement fields, on the contrary, display an unexpected pattern, showing the subsidence of the Coastal Range. Although the magnitude of subsidence recorded by the RTK GPS may appear to be small, they are still consistent over the entire regime and the Central Geological Survey (2018) also reported the subsiding phenomenon ac- cording to the results of leveling survey and campaign GPS (Lu et al. 2018). Our data show that the Lingding Fault acted mainly as a left-lateral strike-slip fault with minor vertical offsets as the regime of the Coastal Range appeared to subside during the 0206 earthquake.

\subsubsection{The Transition Zone}

The GPS results of the transition zone recorded the changes of moving directions between the Milun Fault and the Lingding Fault. The horizontal displacement fields of the foot-wall block for the Milun Fault mainly point to the southeast direction, gradually changing to due south as approaching the Lingding Fault and evolved to the southwest direction when eventually encountering the Lingding Fault. The vertical displacement fields exhibit a prevailing pattern of subsidence over this regime. Although it is not clear whether the tips of the two faults joined, overlapped, or separated in the offshore, it is clear that the Milun Fault and the Lingding Fault acted with different kinematics during the 0206 earthquake. As the two asperities broke through and produced the surface ruptures, the transition zone was forced to accommodate the strains induced by them. From our GPS results, we can evidently see the turning of the moving directions and the significant subsidence in the Nanbin area. A careful simulation regarding the geometry and orientation of the two faults in the future may help to further interpret the complex pattern.

\subsection{The Seismotectonic Implications}

By combining Differential SAR Interferometry, Pixel Offset, and both records from the campaign and continuous GPS stations, Yen et al. (2019) built a coseismic displacement model with a complex wrench tectonic for the 0206 earthquake. Our network RTK data greatly resembles the values calculated by Yen et al. (2019), showing an agreement with their wrench model (Fig. 6). When comparing the two sets of values, the horizontal displacements are highly consistent both in magnitude and direction. The vertical displacement, however, are similar to the first order and dissimilar in detail. Particularly, the vertical displacement in the Coastal Range from our network RTK indicated a clear subsidence in almost all the benchmarks measured, in contrast to the displacement model. Although measurement in vertical direction by network RTK generally have lower precision, all our measurements from the Coastal Range showed subsidence of different values against the reference area and the results were consistent with continuous GPS of the YENL station. The slight difference between our data and the displacement model could also be attributed to the different time span of the observation since our results showed the changes in position between 2012 - 2015 and after the earthquake in 2018, while most other coseismic observations concentrate 

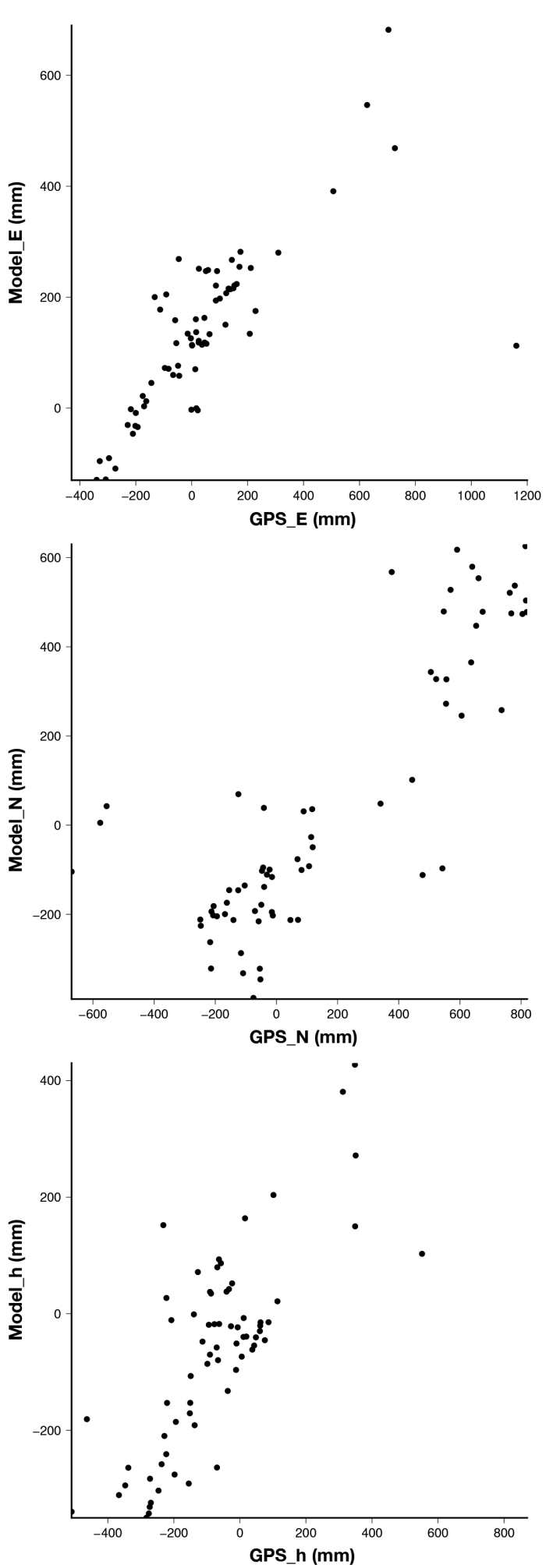

Fig. 6. Comparisons of the GPS measurements used in this study and the modeled coseismic 3D displacement from Yen et al. (2019). In general, all three components of displacement (east-west, north-south, up-down) measured from network-RTK and 3D displacement model are linearly correlated. The correlation in the north-south direction was slightly weaker than the other two directions, probably due to the ambiguity of radar satellite data in the north-south direction. solely on the very short time before and after the earthquake, it is possible that the long term trend in the Coastal Range were incorporated in the measurements. [By referring to the geodetic data of Lu et al. (2018), the displacement volumes between 2013 and 2017 fell between 9.6 and $63.2 \mathrm{~mm} \mathrm{yr}^{-1}$, roughly in line with the measurement results.]

To sum up, the network GPS offered a solid dataset that recognized the movement of the two prominent faults and the terranes in between. GPS results show that the deformation was not localized along the Milun Fault and there were extensive off-fault deformation across the Milun Terrace and the Beibin area. The change and disturbance of the displacement fields at the Nanbin area not only pinned out the location of the Milun Fault but also showed how the strains were accommodated at the junction of two faults. The Milun Fault and the Lingding Fault generated similar magnitude of left-lateral displacements during the 0206 earthquake but behaved very differently in their vertical displacement fields. The underlying kinematics will require more knowledge on the geometry, orientation of the two faults and the deep architecture resulting from the regional tectonics. Our results suggest that a long-term monitoring of surface deformation and a denser network for the two faults will be crucial to provide the best coverage in the future.

Acknowledgements We thank the Eastern Taiwan Earthquake Research Center of National Dong Hwa University (NDHU) and Baiyue Technology of Taiwan Co., Ltd. for providing the instruments to collect the measurements. We are grateful to the enormous help on the intense field investigation from our fellow colleagues and students at the College of Environmental Studies, NDHU. We also thank the two anonymous reviewers to offer valuable suggestions and comments on the manuscript. This research is funded by the Ministry of Science and Technology, Taiwan, R.O.C. (Grant no. MOST 107-2119-M-259-002).

\section{REFERENCES}

Central Geological Survey, 2018: Geological report of 2018 Hualien Earthquake, Central Geological Survey report, Taipei, 131 pp. (in Chinese)

Central Weather Bureau, 2018: Seismicity Report of No. 22 Earthquake, Central Weather Bureau, Taipei. Available at https://scweb.cwb.gov.tw/graphiccontent.aspx/ earthquake/details/ee2018020623504162022.

Chen, C.-Y., 1974: Verification of the north-northeastward movement of the Coastal Range, eastern Taiwan, by Re-Triangulation. Bull. Geol. Surv. Taiwan, 24, 119123.

Chen, W.-S, I.-C. Lin, Y.-C. Yen, C.-C. Yang, C.-Y. Chi, N.-W. Huang, C.-W. Lin, W.-S. Lin, C.-S. Hou, Y.C. Liu, Y.-H. Lin, T.-S. Shih, and S.-T. Lu, 2008: Fault segmentation of the Longitudinal Valley Fault in 
Eastern Taiwan: Evidence from paleoseismic investigations and GPS observations. Spec. Publ. Cent. Geol. Surv., 20, 165-191.

Guan, Z.-K., W.-F. Sun, P.-Y. Jhong, H. Kuo-Chen, and W.-Y. Chang, 2018: Dense seismic array for the 2018 Mw 6.4 Hualien earthquake I: Aftershock sequence. Proceedings, 2018 Annual Congress of Geological Society Located in Taipei \& Chinese Taipei Geophysical Society, May 02-03, Chiayi, Taiwan.

Hsu, T. L., 1955: Earthquake of Taiwan. Quarterly Journal of the Taiwan Bank, 7, 39-63.

Hsu, Y.-C., C.-P. Chang, H. Kuo-Chen, J.-Y. Yen, C.-C. Wang, B.-L. Wu, Y.-H. Chang, W.-Y. Chang, and C.-H. Lu, 2018: Investigating surface ruptures and coseismic deformation of 0206 Hualien Earthquake using field survey and remote sensing. Sino-Geotechnics, 156, $15-24$

Hsu, Y.-C., C.-P. Chang, J.-Y. Yen, H. Kuo-Chen, and C.-C. Wang, 2019: Investigating the structure of the Milun fault from surface ruptures of the 2018 Hualien earthquake. Terr. Atmos. Ocean. Sci., 30, 337-350, doi: 10.3319/TAO.2018.09.28.01. [Link]

Huang, B.-S., C.-J. Lin, W.-J. Huang, Z.-X. Jiang, H.-Z. Qio, and Y.-L. Chen, 2018: Hualian Earthquake, Milun fault, strong motion data, source rupture, rupture directivity. in Proceedings, 2018 Annual Congress of Geological Society Located in Taipei \& Chinese Taipei Geophysical Society, May 02-03, Chiayi, Taiwan.

Huang, S.-Y., J.-Y. Yen, B.-L. Wu, I.-C. Yen, and R. Y. Chuang, 2019: Investigating the Milun Fault: The coseismic surface rupture zone of the 2018/02/06 $\mathrm{M}_{\mathrm{L}} 6.2$ Hualien earthquake, Taiwan. Terr. Atmos. Ocean. Sci., 30, 311-335, doi: 10.3319/TAO.2018.12.09.03. [Link]

Jiang, Y.-L., Z. Huang, Z.-W. Huang, Z.-Y. You, and M.H. Huang, 2018: Surveys and Analysis of near ground deformation in 20180206 Hualien Earthquake. Poster presented at the 2018 annual congress of Geological Society Located in Taipei \& Chinese Taipei Geophysical Society, May 02-03, Chiayi, Taiwan.

Kao, Y.-H., 2016: Faults activities and crustal deformation of Hualien city analysed by geodetic measurements and geophysical prospecting. Master Thesis, National Dong Hwa University, Hualien, Taiwan, 104 pp.

Kuo-Chen, H., Y.-M. Wu, C.-H. Chang, J.-C. Hu, and W.-S. Chen, 2004: Relocation of Eastern Taiwan Earthquakes and Tectonic Implications. Terr. Atmos. Ocean. Sci., 15, 647-666, doi: 10.3319/TAO.2004.15.4.647(T). [Link]

Lin, C.-W., H.-C. Chang, S.-T. Lu, T.-S. Shih, and W.-J. Huang, 2000: An Introduction to the Active Faults of Taiwan, Central Geological Survey, Taipei, Taiwan, $122 \mathrm{pp}$.

Lin, C.-W., W.-S. Chen, Y.-C. Liu, and P.-T. Chen, 2009: Active Faults of Eastern and Southern Taiwan, Central Geological Survey, Taipei, Taiwan, 178 pp.
Lin, Y.-S., R. Y. Chuang, J.-Y. Yen, Y.-C. Chen, Y.-T. Kuo, B.-L. Wu, S.-Y. Huang, and C.-J. Yang, 2019: Mapping surface breakages of the 2018 Hualien earthquake by using UAS photogrammetry. Terr. Atmos. Ocean. Sci., 30, 351-366, doi: 10.3319/TAO.2018.12.09.02. [Link]

Lu, S.-T., C.-L. Chen, Z.-Y. Chen, Y.-C. Liu, P.-T. Chen, C.-W. Hsu, J.-M. Jhuang, J.-R. Jheng, S.-T. Chen, C.-Y. Huang, and J.-Y. Lu, 2018: 20180206 Hualien Earthquake Geological Survey Report, Central Geological Survey, Taipei, Taiwan, 115 pp.

Pathier, E., B. Fruneau, B. Deffontaines, J. Angelier, C.P. Chang, S.-B. Yu, and C.-T. Lee, 2003: Coseismic displacements of the footwall of the Chelungpu fault caused by the 1999, Taiwan, Chi-Chi earthquake from InSAR and GPS data. Earth Planet. Sci.Lett., 212, 7388, doi: 10.1016/S0012-821X(03)00244-9. [Link]

Saghravani, S. R., S. bin Mustapha, and S. F. Saghravani, 2009: Accuracy comparison of RTK-GPS and automatic level for height determination in land surveying. MASAUM Journal of Reviews and Surveys, 1, 10-13.

Shyu, J. B. H., Y.-R. Chuang, Y.-L. Chen, Y.-R. Lee, and C.-T. Cheng, 2016: A new on-land seismogenic structure source database from the Taiwan Earthquake Model (TEM) project for seismic hazard analysis of Taiwan. Terr. Atmos. Ocean. Sci., 27, 311-323, doi: 10.3319/TAO.2015.11.27.02(TEM). [Link]

Sun, W.-F., Z.-K. Guan, P.-Y. Jhong, H. Kuo-Chen, and W.-Y. Chang, 2018: 2018 Mw6.4 Hualien Earthquake, dense seismic array, seismic tomography, velocity model of Hualien area. Proceedings, 2018 Annual Congress of Geological Society Located in Taipei \& Chinese Taipei Geophysical Society, May 02-03, Chiayi, Taiwan.

Taiwan Weather Bureau, 1952: Earthquake Report in 1951, $83 \mathrm{pp}$.

Wang, C.-Y., H. Kuo-Chen, H.-Y. Kuo, and Z.-K. Guan, 2018: Examining Costal Range Mountain Building from 10 Seismic Profiles across the Longitudinal Valley. Proceedings, 2018 Annual Congress of Geological Society Located in Taipei \& Chinese Taipei Geophysical Society, May 02-03, Chiayi, Taiwan.

Yen, J.-Y., C.-H. Lu, C.-P. Chang, A. J. Hooper, Y.-H. Chang, W.-T. Liang, T.-Y. Chang, M.-S. Lin, and K.S. Chen, 2011: Investigating Active deformation in the northern Longitudinal Valley and City of Hualien in eastern Taiwan using persistent scatterer and smallbaseline SAR interferometry. Terr. Atmos. Ocean.Sci., 22, 291-304, doi: 10.3319/TAO.2010.10.25.01(TT). [Link]

Yen, J.-Y., C.-H. Lu, R. J. Dorsey, H. Kuo-Chen, C.-P. Chang, C.-C. Wang, R. Y. Chuang, Y.-T. Kuo, C.-Y. Chiu, Y.-H. Chang, F. Bovenga, and W.-Y. Chang, 2019: Insights into Seismogenic Deformation during 
the 2018 Hualien, Taiwan, Earthquake Sequence from InSAR, GPS, and Modeling. Seismol. Res. Lett., 90, 78-87, doi: 10.1785/0220180228. [Link]

Yu, M.-S., 1997: Investigation of active faults on the Longitudinal Valley. Ph.D. Thesis, National Taiwan University, Taipei, Taiwan, $141 \mathrm{pp}$.

Yu, S.-B., D. D. Jackson, G.-K. Yu, and C.-C. Liu, 1990: Dislocation model for crustal deformation in the Longitudinal Valley area, Eastern Taiwan. Tectonophys- ics, 183, 97-109, doi: 10.1016/0040-1951(90)90190-J. [Link]

Yu, S.-B., L.-C. Kuo, Y.-J. Hsu, H.-H. Su, C.-C. Liu, C.-S. Hou, J.-F. Lee, T.-C. Lai, C.-C. Liu, C.-L. Liu, T.-F. Tseng, C.-S. Tsai, and T.-C. Shin, 2001: Preseismic Deformation and coseismic displacements associated with the 1999 Chi-Chi, Taiwan, earthquake. Bull. Seismol.Soc.Am.,91,995-1012, doi: 10.1785/0120000722. [Link] 